\title{
Vacuum Assisted Closure (VAC) and Platelet-Rich Plasma (PRP): A Successful Combination in a Challenging Case of Gastroschisis
}

\author{
Vincenzo Domenichelli*, Simona Straziuso, Maria Domenica Sabatino, Silvana Federici \\ Pediatric Surgical Unit, “Infermi” Hospital, AUSL Romagna, Rimini, Italy \\ Email: ${ }^{*}$ zodott@me.com
}

Received 13 August 2015; accepted 20 September 2015; published 23 September 2015

Copyright @ 2015 by authors and Scientific Research Publishing Inc.

This work is licensed under the Creative Commons Attribution International License (CC BY).

http://creativecommons.org/licenses/by/4.0/

c) (7) Open Access

\begin{abstract}
Giant gastroschisis could be a surgical challenge concerning the abdominal wall reconstruction. Many techniques have been described for both primary or staged closure but sometimes neither of them is succesful in all patients. We are presenting the combined use of Vacuum Assisted Closure (VAC) and Platelet-Rich Plasma (PRP) to improve the result in this difficult case. The use of VAC device is a well known procedure in the treatment of adult difficult wounds closure. It consists of a sponge applied directly on the abdominal wall defect, covered with a transparent dressing and connected to a controlled continuous negative pressure system [1]. Platelet-rich plasma (PRP) is an autologous concentration of human platelets in a small volume of plasma. Due to this combination it provides multiple growth and healing factors actively secreted by platelets which have been shown to begin and accelerate wound healing [2] [3]. The association between VAC and PRP was effective in the shrinkage and reduction of the abdominal defect. Fifteen months after the removal of the VAC device the fascia appears competent with a cutaneus scar that will need a plastic correction in the future. The VAC should be considered as a helpful and effective device in case of complicated giant gastroschisis or omphalocele when traditional treatment is not sufficient.
\end{abstract}

\section{Keywords}

Vacuum Assisted Closure, Gastroschisis, Platelet-Rich Plasma, Abdominal Wall Defect

\section{Introduction}

Gastroschisis is a relatively common congenital malformation of the abdominal wall.

\footnotetext{
${ }^{*}$ Corresponding author.
}

How to cite this paper: Domenichelli, V., Straziuso, S., Sabatino, M.D. and Federici, S. (2015) Vacuum Assisted Closure (VAC) and Platelet-Rich Plasma (PRP): A Successful Combination in a Challenging Case of Gastroschisis. Open Journal of Pediatrics, 5, 274-278. http://dx.doi.org/10.4236/ojped.2015.53041 
In the last decade the treatment of choice has been the primary closure. After the description of Bianchi's technique many of these patients have been treated in NICU with a manual reduction of the bowel into the abdominal cavity [4].

Whenever this approach cannot be applied the traditional silo bag for staged reduction is used.

We are describing a case in which all the possible ways have been used to reach the closure of the abdominal defect but due to the underdevelopment of the abdominal cavity and the presence of thickened intestinal wall the reduction was not possible using traditional techniques.

\section{Case Report}

F. M., female, was born via vaginal delivery at 34th week of gestational age with a very huge gastroschisis which was diagnosed during a late prenatal ultrasound. At birth the Apgar scores were $9 / 10$ and the infant weight was 2500 grams.

The patient was in good clinical condition and then transferred to the neonatal intensive care unit (NICU) of our hospital. The majority of the intestinal loops were outside the abdominal wall and were immediately covered by a sterile plastic bag. At a first examination a "mesenterium commune" and a plastic peritonitis of the outer loops were seen.

After an unsuccesful attempt of manual reduction [4], a surgical procedure with partial reduction of the bowels into the abdominal cavity, appendectomy and resection of an ileal atresia was performed in the operating room. An Alexis ${ }^{\circledR}$ wound retractor was then used as a Silo bag to contain the remaining extra-abdominal loops for a later stage reduction (Figure 1).

In the immediate postoperative period the patient had stable vital signs with a moderate dyspnea.

Further investigations in the NICU didn't show any associated congenital abnormality. The child was managed with antibiotic therapy and total parenteral nutrition.

During the following days several progressive reductions were attempted and in $9^{\text {th }}$ postoperative day a GoreTex ${ }^{\circledR}$ patch was placed to close the abdominal wall defect.

On the $19^{\text {th }}$ day of life the baby girl passed normal stools.

Eleven days after the positioning of the patch, an inflammatory infiltration of the wound occurred with an almost complete dehiscence, presenting the underneath Gore-Tex on the surface.

We then planned to start a VAC treatment (ActiVAC ${ }^{\circledR}$, KCI System). The black sponge (KCI VAC ${ }^{\circledR}$ Granufoam $^{\mathrm{TM}}$ ) was applied on the Gore-Tex mesh which was partially detached (Figure 2). We applied the VAC with a negative pressure, ranging from 50 to $75 \mathrm{mmHg}$ which kept the wound clean, lowering the risk of infections and helping the closure of the wound itself.

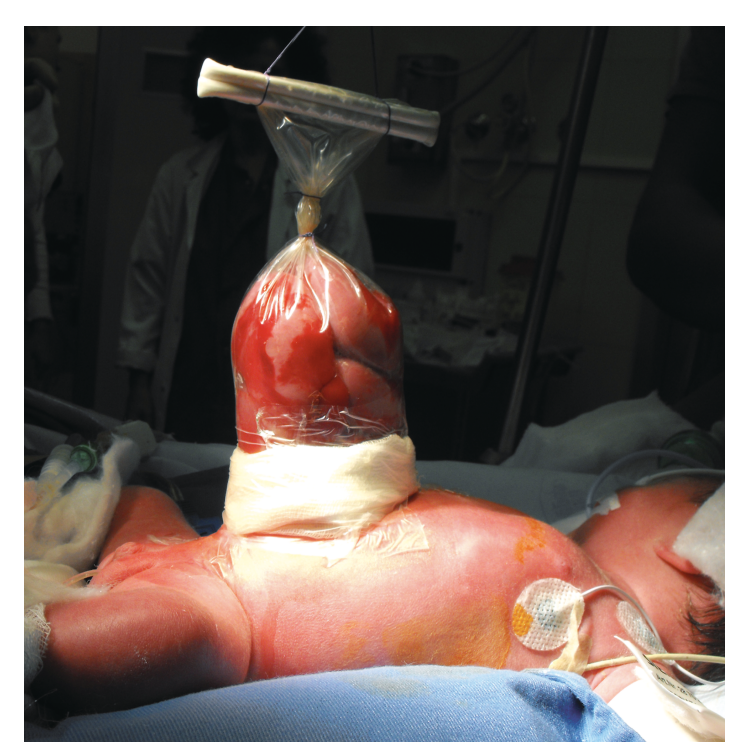

Figure 1. The Alexis ${ }^{\circledR}$ wound retractor applied as a Silo bag. 
The VAC was applied for 33 days and changed every 48/72 hours. Granulation tissue was discovered under the patch which at this point was completely removed and therefore we decided to start a PRP treatment to further support the healing process. The PRP was continued for 7 days [5]. VAC treatment was continued for other 14 days. The patient was sent home at 2 months of life and the VAC set changed every 72/96 hrs on an outpatient basis without sedation. Towards the end of the treatment the device was changed at longer intervals. Subsequently the wound was covered with hydrocolloidal adhesive medication until its complete recovery.

The initial abdominal wall defect was $6 \times 2.5 \mathrm{~cm}$ and decreased throughout the period of treatment (Figure 3).

During the treatment no infections occurred. We observed a complete wound closure; the abdominal wall appears competent without ventral hernia with acceptable skin scar which, of course, will need further plastic surgery (Figure 4).

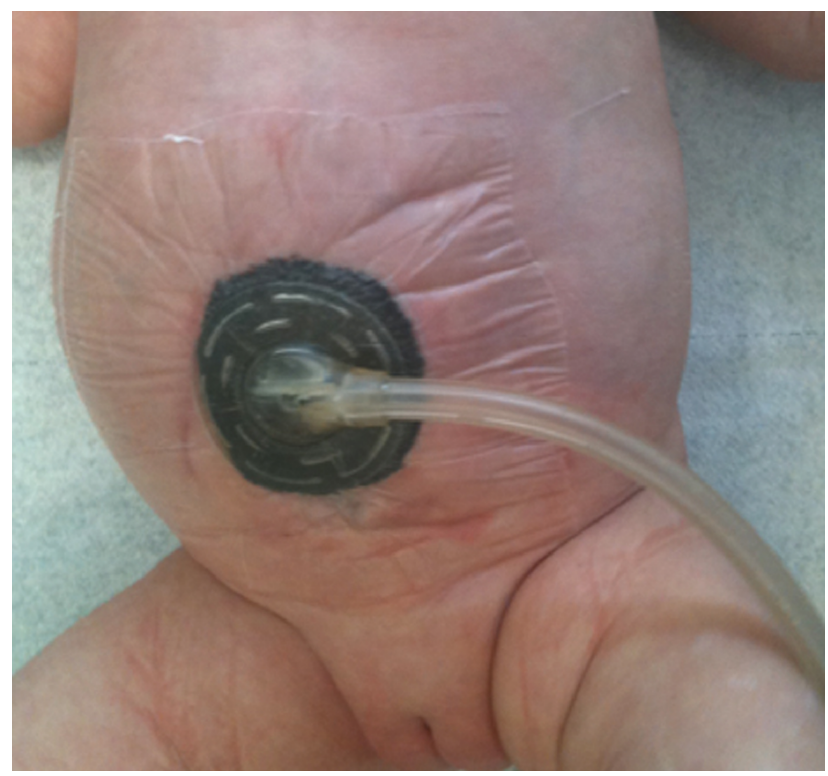

Figure 2. The VAC device during negative pressure.

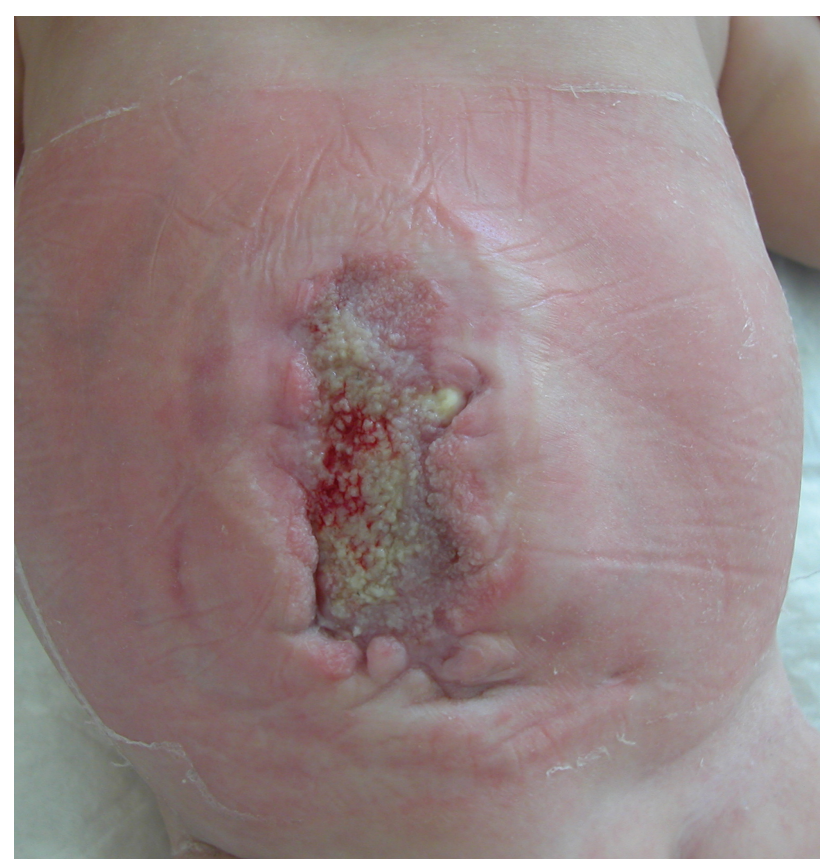

Figure 3. The abdominal wall defect after the PRP treatment. 


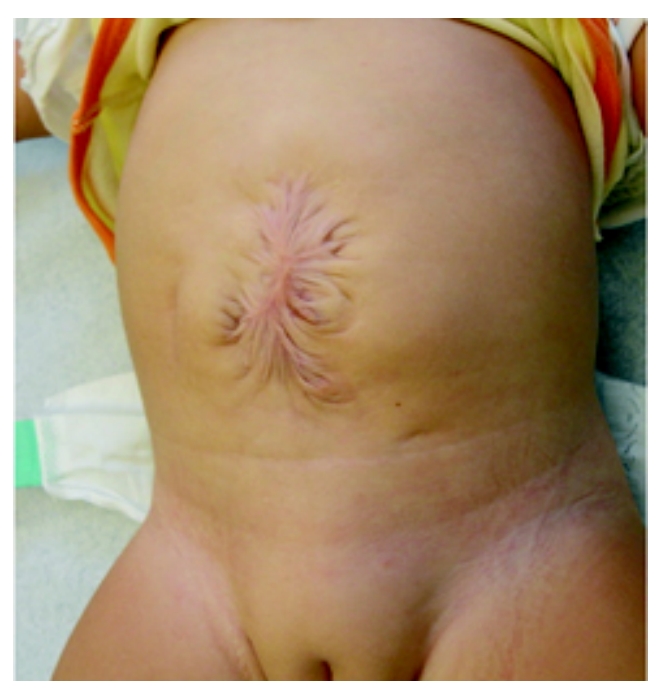

Figure 4. The final scar at complete healing.

\section{Discussion}

The VAC therapy has been reported as a successful alternative also in treating difficult cases of abdominal wall defects in children and newborns in NICU [1] [6] [7].

Vacuum-assisted closure appears to increase microcirculation, granulation tissue coverage and contraction rate and to decrease wound edema and infections [8]-[10]. Its use helped the reduction of abdominal wall defects in a short period of time keeping the abdominal cavity dry and lowering the risk of wound infections.

It is simple to apply and to use at the bedside or on an outpatient basis. It is well tolerated in the pediatric age [11].

Topical treatment using platelet derived factors has increasingly been described as being capable of accelerating wound healing and tissue repair [12].

The use of prp in pediatric population is not very common - as shown by the little international literature available [3] [13] — but we believe that in some selected cases could be of great help for its peculiar properties.

Therefore VAC devices and PRP together, should be considered as a helpful and effective alternative in complicated giant gastroschisis or omphalocele when traditional treatments are not sufficient.

\section{References}

[1] Kilbride, K.E., Cooney, D.R. and Custer, M.D. (2006) Vacuum-Assisted Closure: A New Method for Treating Patients with Giant Omphalocele. Journal of Pediatric Surgery, 41, 212-215. http://dx.doi.org/10.1016/j.jpedsurg.2005.10.003

[2] Marx, R.E. (2004) Platelet-Rich Plasma: Evidence to Support Its Use. Journal of Oral and Maxillofacial Surgery, 62, 489-496. http://dx.doi.org/10.1016/j.joms.2003.12.003

[3] Sidman, J.D., Lander, T.A., et al. (2008) Platelet-Rich Plasma for Pediatric Tonsillectomy Patients. Laryngoscope, 118, 1765-1767. http://dx.doi.org/10.1097/MLG.0b013e31817f18e7

[4] Bianchi, A. and Dickson, A.P. (1998) Elective Delayed Reduction and No Anesthesia: "Minimal Intervention Management" for Gastrochisis. Journal of Pediatric Surgery, 33, 1338-1340. http://dx.doi.org/10.1016/S0022-3468(98)90002-1

[5] Baird, R., Gholoum, S., Laberge, J.M., et al. (2010) Management of a Giant Omphalocele with an External Skin Closure System. Journal of Pediatric Surgery, 45, 17-20. http://dx.doi.org/10.1016/j.jpedsurg.2010.05.004

[6] Gabriel, A. and Gollin, G. (2006) Management of Complicated Gastroschisis with Porcine Small Intestinal Submucosa and Negative Pressure Wound Therapy. Journal of Pediatric Surgery, 41, 1836-1840. http://dx.doi.org/10.1016/j.jpedsurg.2006.06.050

[7] Fenton, S.J., Dodgion, C.M., Meyer, R.L., et al. (2007) Temporary Abdominal Vacuum-Packing Closure in the Neonatal Intensive Care Unit. Journal of Pediatric Surgery, 42, 957-961. http://dx.doi.org/10.1016/j.jpedsurg.2007.01.029

[8] McCord, S.S., Naik-Mathuria, B.J., Murphy, K.M., et al. (2007) Negative Pressure Therapy Is Effective to Manage a Variety of Wounds in Infants and Children. Wound Repair and Regeneration, 15, 296-301. 
http://dx.doi.org/10.1111/j.1524-475X.2007.00229.x

[9] Miller, P.R., Meredith, J.W., Johnson, J.C., et al. (2004) Prospective Evaluation of Vacuum-Assisted Fascial Closure after Open Abdomen. Annals of Surgery, 239, 608-616. http://dx.doi.org/10.1097/01.sla.0000124291.09032.bf

[10] Fleck, T., Simon, P., Burda, G., et al. (2006) Vacuum Assisted Closure Therapy for the Treatment of Sternal Wound Infections in Neonates and Small Infants. Interactive CardioVasc Thoracic Surgery, 5, 285-288. http://dx.doi.org/10.1510/icvts.2005.122424

[11] Butter, A., Emran, M., Al-Jazaeri, A., et al. (2006) Vacuum-Assisted Closure for Wound Management in the Pediatric Population. Journal of Pediatric Surgery, 41, 940-942. http://dx.doi.org/10.1016/j.jpedsurg.2006.01.061

[12] Mazzucco, L., Borzini, P. and Gope, R. (2010) Platelet-Derived Factors Involved in Tissue Repair from Signal to Function. Transfusion Medicine Reviews, 24, 218-234. http://dx.doi.org/10.1016/j.tmrv.2010.03.004

[13] Nagaveni, N.B., Praveen, R.B., Umashankar, K.V., et al. (2010) Efficacy of Platelet-Rich Plasma (PRP) in Bone Regeneration after Cyst Enucleation in Pediatric Patients-A Clinical Study. Journal of Clinical Pediatric Dentistry, 35, 81-87. http://dx.doi.org/10.17796/jcpd.35.1.q69168v5268234k9 